\title{
Genistein inhibits the proliferation and differentiation of MCF-7 and 3T3-L1 cells via the regulation of ER $\alpha$ expression and induction of apoptosis
}

\author{
EUN JEONG CHOI, JAE YEON JUNG and GUN-HEE KIM
}

Plant Resources Research Institute, Duksung Women's University, Seoul 132-714, Republic of Korea

Received December 30, 2013; Accepted May 6, 2014

DOI: $10.3892 /$ etm.2014.1771

\begin{abstract}
The present study investigated the effect of the phytochemical genistein on the proliferation and differentiation of MCF-7 and 3T3-L1 cells via the regulation of estrogen receptor- $\alpha(E R \alpha)$ expression and the induction of apoptosis. When MCF-7 human breast cancer cells were treated with 50, 100,150 and $200 \mu \mathrm{M}$ genistein for 24,48 or $72 \mathrm{~h}$, cell growth was significantly decreased in a concentration-dependent manner. Notably, the patterns of ER $\alpha$ expression and proliferation in MCF-7 cells treated with genistein were similar. Furthermore, ER $\alpha$ expression in differentiating 3T3-L1 cells was significantly inhibited by $48 \mathrm{~h}$ treatment with $50 \mu \mathrm{M}$ genistein, which was selected based on the results of cytotoxicity assays on 3T3-L1 preadipocytes [lactate dehydrogenase (LDH) and 3-(4,5-dimethylthiazol-2-yl)-2,5-diphenyltetrazolium bromide (MTT) viability assays]. Under the same conditions, genistein-induced apoptotic features were observed in MCF-7 and differentiating 3T3-L1 cells. This observation is supported by the finding that $\mathrm{B}$-cell lymphoma $2(\mathrm{Bcl}-2)$ expression was reduced while that of $\mathrm{Bcl}-2$-associated $\mathrm{X}$ protein (Bax) was induced by genistein. The results of the present study suggest that an ER $\alpha$-related pathway and the induction of apoptosis are involved in the proliferation of MCF-7 cells and the differentiation of 3T3-L1 cells.
\end{abstract}

\section{Introduction}

Genistein (4',5,7-trihydroxyisoflavone) is a major isoflavone present in plants, such as soybean, and therefore, in a variety of human foods (1-3). In 1987, it was discovered that genistein is a potent inhibitor of the tyrosine-specific protein kinase activity of the epidermal growth factor receptor (4). Since then, numerous researchers have studied the possible use of

Correspondence to: Dr Eun Jeong Choi, Plant Resources Research Institute, Duksung Women's University, 419 Ssangmun-dong, Tobong-ku, Seoul 132-714, Republic of Korea.

E-mail: ejchoi@duksung.ac.kr

Key words: genistein, 3T3-L1 cells, MCF-7 cells, proliferation, differentiation, estrogen receptor- $\alpha$ genistein as a cancer chemopreventive agent based on the key role of protein tyrosine kinase inhibitors in cancer cell growth and apoptosis $(5,6)$. In support of these studies, several epidemiological reports have revealed significant correlations between genistein consumption and a reduced risk of breast cancer (7-9). Furthermore, a number of studies have demonstrated that genistein exhibits significant anticancer activity against breast tumors in vitro and in vivo $(10,11)$.

Breast cancer belongs to a group of heterogeneous diseases with multiple clinical, molecular and histopathological forms, which makes achieving effective chemotherapy problematic (12). To develop breast cancer therapies, the targeting of estrogen receptor- $\alpha(\mathrm{ER} \alpha)$, which is expressed in $\sim 70 \%$ of breast cancers and which makes it difficult to obtain a response to cancer drug treatment $(13,14)$, requires consideration.

Therefore, the aim of the present study was to investigate the proliferative effects and induction of apoptosis by genistein via $\mathrm{ER} \alpha$-related pathways in MCF-7 human breast cancer cells and 3T3-L1 mouse preadipocytes.

\section{Materials and methods}

Reagents. All reagents and plasticware used for cell culture, including fetal bovine serum (FBS), media and antibiotics, were purchased from Invitrogen Life Technologies (Carlsbad, CA, USA) and Corning Incorporated Life Sciences (Corning, NY, USA). Insulin, dexamethasone, 3-isobutyl-1-methylxanthine (IBMX) and 3-(4,5-dimethylthiazol-2-yl)-2,5-diphenyltetrazolium bromide (MTT) were purchased from Sigma-Aldrich Co. (St. Louis, MO, USA). The protein analysis reagent and antibodies were purchased from Bio-Rad Laboratories, Inc. (Hercules, CA, USA) and Santa Cruz Biotechnology, Inc. (Santa Cruz, CA, USA), respectively. Genistein was purchased from LC Laboratories (Woburn, MA, USA) and dissolved in dimethyl sulfoxide (DMSO; final concentration of $0.1 \%$ in medium).

Cell culture. The MCF-7 human breast cancer cells and 3T3-L1 mouse preadipocytes were purchased from the Korean Cell Line Bank (Seoul, South Korea) and American Type Culture Collection (Manassas, VA, USA), respectively, for use in the present study. The cells were maintained in Roswell Park Memorial Institute (RPMI)-1640 medium or Dulbecco's modified Eagle's medium (DMEM) supplemented with 10\% FBS 
and antibiotics (50 U/ml penicillin and $50 \mu \mathrm{g} / \mathrm{ml}$ streptomycin) at $37^{\circ} \mathrm{C}$ in a humidified atmosphere containing $5 \% \mathrm{CO}_{2}$. Two days subsequent to reaching confluence (designated as day 0), DMEM containing 10\% FBS and differentiation inducers $(10 \mu \mathrm{g} / \mathrm{ml}$ insulin, $0.5 \mu \mathrm{M}$ dexamethasone and $0.5 \mathrm{mM}$ IBMX) were added to the 3T3-L1 cells to induce differentiation.

MCF-7 cell proliferation assay. MCF-7 cell proliferation was examined using MTT assays. Cells were plated at $2.5-5 \times 10^{5}$ cells/ well in a 96-well tissue culture plate and incubated for $24 \mathrm{~h}$ following which they were exposed to genistein solutions at concentrations of 50,100,150 and $200 \mu \mathrm{M}$. Following incubation for 24,48 and $72 \mathrm{~h}$, the plated cells were incubated with MTT (final concentration $0.5 \mathrm{mg} / \mathrm{ml}$; Sigma-Aldrich) for $4 \mathrm{~h}$ at $37^{\circ} \mathrm{C}$. The medium was discarded from the plates and $100 \mu \mathrm{l}$ DMSO was added to each well. The plates were incubated for $5 \mathrm{~min}$ at room temperature whilst being shaken, so that the complete dissolution of formazan was achieved. The absorbance of MTT formazan was determined at $540 \mathrm{~nm}$ using an ultraviolet-visible (UV/VIS) spectrophotometric plate reader (EMax; Molecular Devices, LLC, Sunnyvale, CA, USA).

Cytotoxicity assay using 3T3-L1 cells. Cellular toxicity was measured in 3T3-L1 preadipocytes using MTT and LDH assays with various concentrations of genistein $(5-100 \mu \mathrm{M})$ for 24,48 and $72 \mathrm{~h}$. To measure lactate dehydrogenase (LDH) release, $100 \mu \mathrm{l} /$ well supernatant medium was transferred to the corresponding well of an optically clear 96-well flat-bottom microtiter plate and analyzed using an LDH cytotoxicity detection kit (Takara Bio, Inc., Otsu, Japan).

Apoptosis detection. Apoptotic morphological changes were identified by the 4',6-diamidino-2-phenyl-indole (DAPI) staining of MCF-7 cells and differentiating 3T3-L1 cells, which had been treated with genistein at $50 \mu \mathrm{M}$ for $48 \mathrm{~h}$ two days subsequent to reaching confluence. Each cell line was seeded on poly-L-lysine-coated slides and fixed with $4 \%$ methanol-free formaldehyde for $30 \mathrm{~min}$. Mounting medium containing DAPI was dispersed over the entire slide. The mounted slides were stored at $4^{\circ} \mathrm{C}$ in the dark. Each slide was observed under an LSM700 laser scanning microscope equipped with Zen 2011 software (Carl Zeiss Microscopy GmbH, Jena, Germany).

Immunoblotting. Following the exposure of MCF-7 and differentiating 3T3-L1 cells to genistein, each group of cells was subjected to lysis in radio-immunoprecipitation assay (RIPA) buffer [1\% nonyl phenoxypolyethoxylethanol (NP)-40, $150 \mathrm{mM} \mathrm{NaCl}, 0.05 \%$ deoxycholic acid (DOC), $1 \%$ sodium dodecyl sulfate (SDS) and $50 \mathrm{mM}$ tris(hydroxymethyl)aminomethane (Tris), $\mathrm{pH} \mathrm{7.5]} \mathrm{containing} \mathrm{protease} \mathrm{inhibitors} \mathrm{for} 1 \mathrm{~h}$ at $4^{\circ} \mathrm{C}$. The supernatant was separated by centrifugation and the protein concentration was determined using a Bradford protein assay kit 2 (Bio-Rad). The proteins were then transferred to nitrocellulose membranes $(0.45 \mu \mathrm{m})$. The membranes were blocked with $1 \%$ bovine serum albumin (BSA) for $1.5 \mathrm{~h}$, washed twice with phosphate-buffered saline (PBS) containing $0.2 \%$ Tween-20, and incubated with the respective primary antibodies [cyclin D1, anti-ER $\alpha$, -B-cell lymphoma 2 (-Bcl-2), -Bcl-2-associated X protein (-Bax) and - $\beta$-actin; Santa Cruz Biotechnology, Inc.] overnight at $4^{\circ} \mathrm{C}$. The next

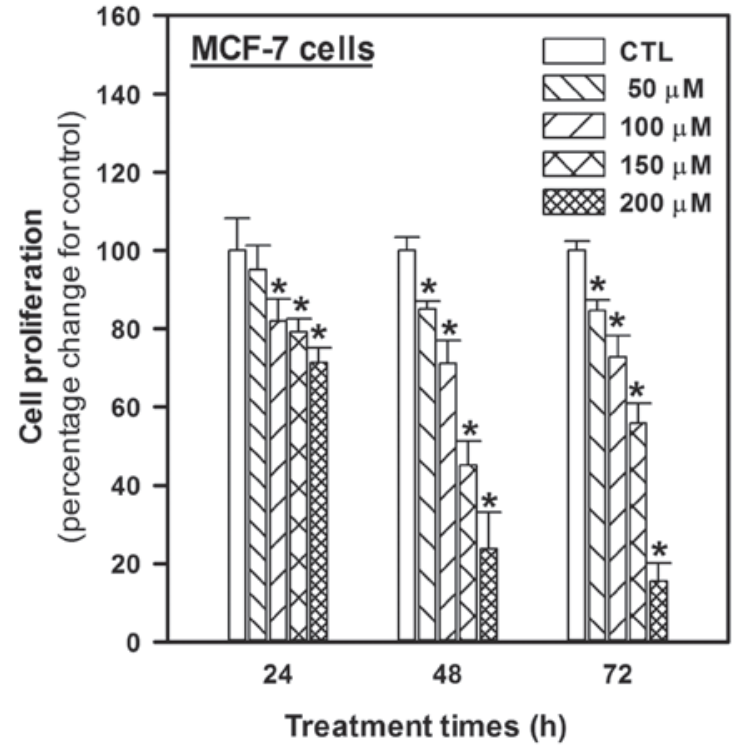

Figure 1. Antiproliferative effects of genistein on MCF-7 cells. MCF-7 cells were exposed to genistein at 50,100, 150 and $200 \mu \mathrm{M}$ for 24,48 and $72 \mathrm{~h}$. All data are reported as the percentage change, as compared with the control (CTL) group (vehicle only). Values are expressed as mean \pm standard deviation. ${ }^{*} \mathrm{P}<0.05$, significantly different from the CTL group.

day, the immunoreaction was continued using secondary rabbit anti-rabbit horseradish-peroxidase-conjugated antibodies following washing for $2 \mathrm{~h}$ at room temperature. Bands were detected with MicroChemi (DNR Bio-Imaging System, Ltd., Jerusalem, Israel) using WesternBright ${ }^{\mathrm{TIN}}$ ECL solution (Advansta Inc., Menlo Park, CA, USA).

Statistical analyses. All values are expressed as means \pm standard deviations. Data were analyzed by an unpaired Student's t-test or one-way analysis of variance followed by Dunnett's multiple comparison test (Sigma Stat software; Jandel Scientific Software, San Rafael, CA, USA). For all comparisons, $\mathrm{P}<0.05$ was considered to indicate a statistically significant difference.

\section{Results}

Antiproliferative activity of genistein toward MCF-7 cells. To investigate the possible anticancer effects of the phytochemical genistein on MCF-7 human breast cancer cells, the present study initially examined the antiproliferative effects of genistein on MCF-7 cells using various concentrations $(50,100,150$ and $200 \mu \mathrm{M})$ of genistein for 24,48 and $72 \mathrm{~h}$ (Fig. 1). Genistein inhibited the growth of MCF-7 cells in a concentration-dependent manner and revealed significant antiproliferative activity under all treatment conditions, with the exception of $50 \mu \mathrm{M}$ for $24 \mathrm{~h}$. The antiproliferative activity of genistein after 48 and $72 \mathrm{~h}$ was stronger than that after $24 \mathrm{~h}$, but there were no differences between 48 and $72 \mathrm{~h}$; reductions of $13,29,55$ and $77 \%$ at $48 \mathrm{~h}$ and $15,27,45$ and $85 \%$ at $72 \mathrm{~h}$ for 50, 100, 150 and $200 \mu \mathrm{M}$ genistein, were noted, as compared with the control levels after 48 and $72 \mathrm{~h}$.

Cytotoxicity of genistein toward 3T3-L1 preadipocytes. To assess the cytotoxicity of genistein, cell growth and LDH 
A

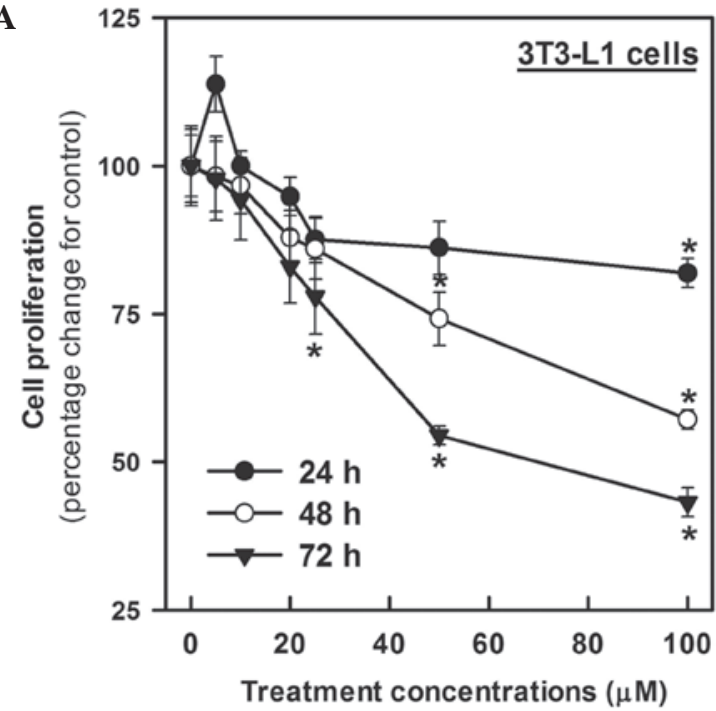

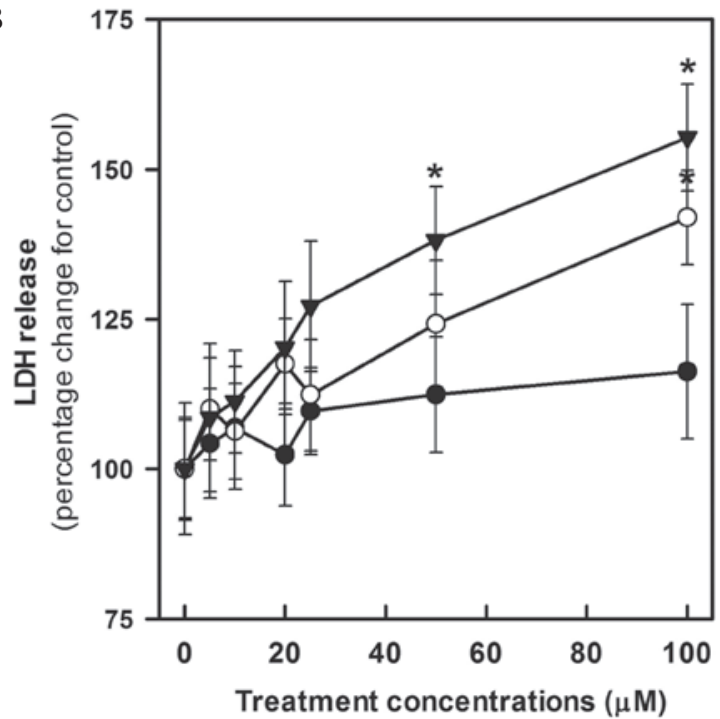

Figure 2. Cytotoxicity of genistein toward 3T3-L1 preadipocytes. (A) 3-(4,5-Dimethylthiazol-2-yl)-2,5-diphenyltetrazolium bromide (MTT) assay. (B) Lactate dehydrogenase (LDH) assay. 3T3-L1 preadipocytes were exposed to genistein at 5, 10, 20, 25, 50 and $100 \mu \mathrm{M}$ for 24, 48 and $72 \mathrm{~h}$. Values are expressed as means \pm standard deviation. " $\mathrm{P}<0.05$, significantly different from the vehicle-only group.

A

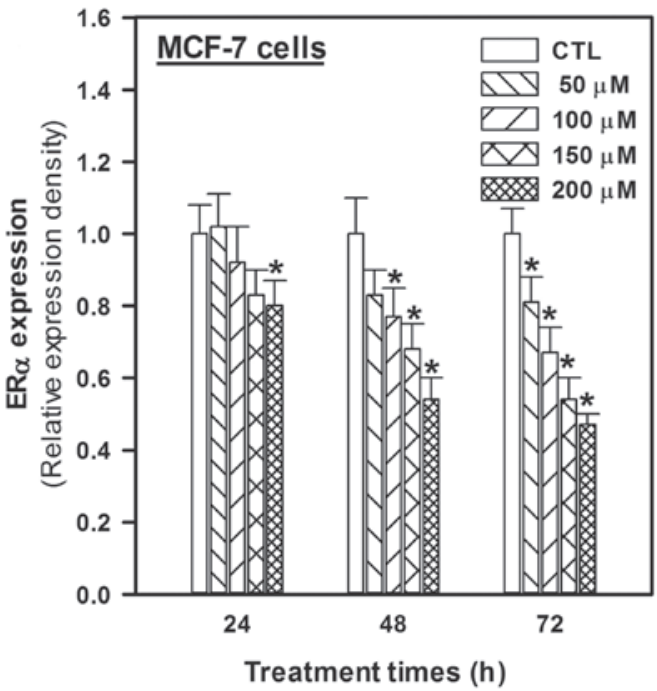

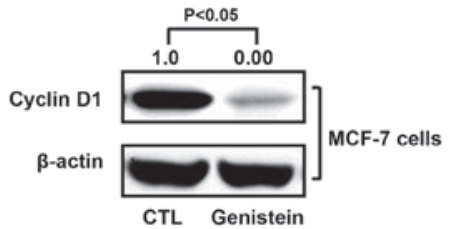

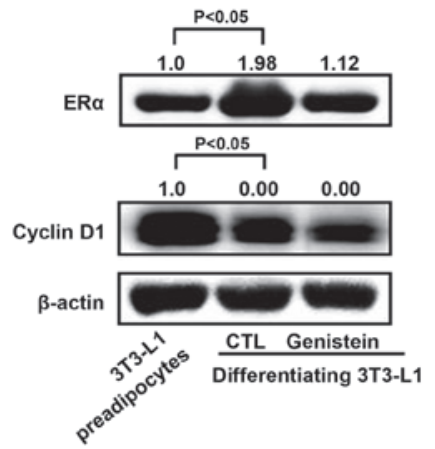

Figure 3. Modulation of estrogen receptor- $\alpha(\mathrm{ER} \alpha)$ and cyclin D1 by genistein in MCF-7 and differentiating 3T3-L1 cells. (A) For determination of ER $\alpha$, MCF-7 cells were exposed to genistein at 50, 100, 150 and $200 \mu \mathrm{M}$ for 24, 48 and $72 \mathrm{~h}$. (B) In addition, 3T3-L1 and MCF-7 cells were exposed to 50 $\mu \mathrm{M}$ genistein for $48 \mathrm{~h}$. Values are expressed as means \pm standard deviations. CTL, control group (vehicle only); ${ }^{*}<0.05$, significantly different from the CTL group.

release were measured in 3T3-L1 cells exposed to genistein at $5-100 \mu \mathrm{M}$ for 24,48 and $72 \mathrm{~h}$. Genistein significantly decreased cell growth after 48 and $72 \mathrm{~h}$ in a concentration-dependent manner [the half maximal inhibitory concentration $\left(\mathrm{IC}_{50}\right)$ for 48 and $72 \mathrm{~h}$ was 111.67 and $77.1 \mu \mathrm{M}$, respectively; Fig. 2]. Moreover, under the same conditions, exposure to genistein for $24 \mathrm{~h}$ caused $\mathrm{LDH}$ release to increase by $4-16 \%$; however, the increase was not statistically significant. After 48 and $72 \mathrm{~h}$, although the release of LDH increased in a concentration- and time-dependent manner, significant inhibition of cell growth was first observed in cells treated with 100 and $50 \mu \mathrm{M}$ genistein for 48 and 72 h, respectively (Fig. 2).

ER $\alpha$, cyclin D1, and Bcl-2 expression in genistein-treated MCF-7 or differentiating 3T3-L1 cells. To elucidate the mechanism of the ER $\alpha$-dependent antiproliferative activity of genistein, cells were exposed to 50, 100, 150 and $200 \mu \mathrm{M}$ genistein for 24, 48 and $72 \mathrm{~h}$. The results revealed that the patterns of ER $\alpha$ expression and proliferation were similar (Fig. 3). ER $\alpha$ expression was downregulated by genistein at all concentrations; furthermore, the effect of genistein was greater after 48 and $72 \mathrm{~h}$. ER $\alpha$ expression was upregulated 1.98-fold in 3T3-L1 cells following inducer treatment for $48 \mathrm{~h}$ as compared with that in the negative control (3T3-L1 preadipocytes, Fig. 3), in order to initiate differentiation. Genistein treatment at a concentration of $50 \mu \mathrm{M}$ for $48 \mathrm{~h}$, which was selected as the effective (no significant cellular toxicity) concentration, restored ER $\alpha$ expression to almost the initial differentiating levels.

Cyclin D1 expression in MCF-7 and 3T3-L1 cells was decreased by treatment with genistein at $50 \mu \mathrm{M}$ for $48 \mathrm{~h}$ (Fig. 3). 


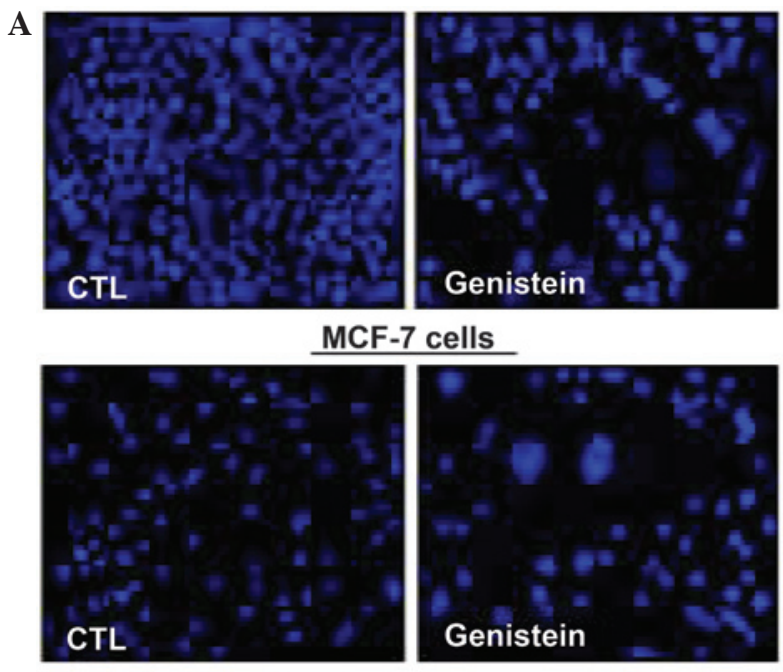

$\underline{3 T 3-L 1 \text { cells }}$

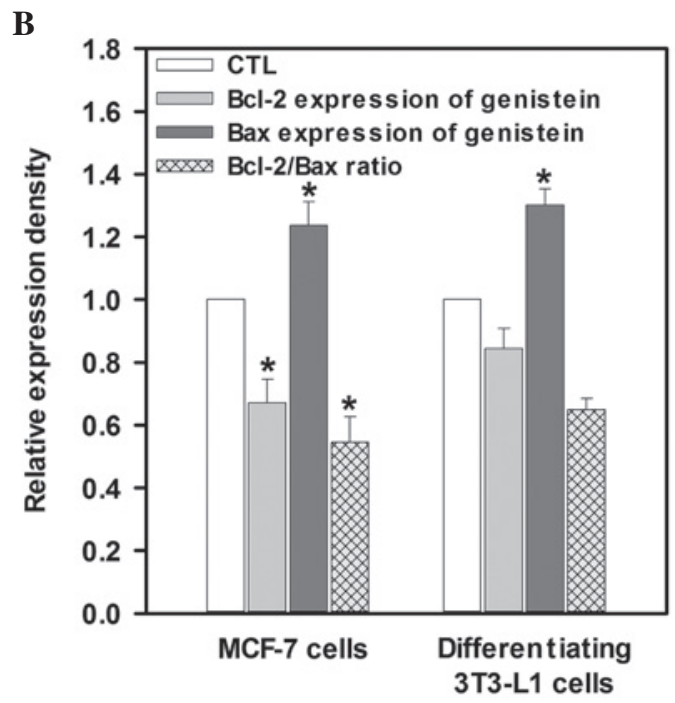

Figure 4. Induction of apoptosis by genistein. Apoptotic changes were detected by (A) 4',6-diamidino-2-phenyl-indole (DAPI) staining and (B) measurement of the B-cell lymphoma 2 (Bcl-2)/Bcl-2-associated X protein (Bax) ratio. The standard deviations in all the control groups for MCF-7 and 3T3-L1 cells are $<0.12$. Values are expressed as means \pm standard deviations. CTL, control group (vehicle only); ${ }^{*} \mathrm{P}<0.05$, significantly different from the CTL group.

Apoptosis inducing effect of genistein on MCF-7 and differentiating 3T3-L1 cells. As shown in Fig. 4, exposure of MCF-7 cells to genistein at a concentration of $50 \mu \mathrm{M}$ for $48 \mathrm{~h}$ produced apoptotic morphological features, including cell shrinkage and dot-shaped nuclear fragments. Compared with the control cells, exposure to genistein resulted in an increase in apoptotic morphological features on both MCF-7 and differentiating 3T3-L1 cells. This result is supported by the fact that genistein significantly decreased the Bcl-2/Bax expression ratio by $45.5 \%$ and $35.2 \%$ in MCF-7 and differentiating 3T3-L1 cells, respectively, compared with their respective control levels ( $\mathrm{P}<0.05$, Fig. 4).

\section{Discussion}

In the present study, the antiproliferative effects of genistein on MCF-7 cells at concentrations of 50, 100, 150 and $200 \mu \mathrm{M}$ were investigated. Genistein is a phytoestrogen, a plant-derived phenolic compound that structurally mimics the hormone $17 \beta$-estradiol (15). Thus, the effects of genistein on estrogen receptors (ERs) are both agonistic and antagonistic $(16,17)$, and may explain the biphasic effect of genistein on MCF-7 cell proliferation. A previous study (18) revealed that the antiproliferative effect of genistein on MCF-7 cells was biphasic (inhibitory at high concentrations and stimulatory at low concentrations). This result is consistent with that of other previous studies demonstrating that estrogen-like bioactive molecules may stimulate breast cancer cell growth (19-21). In the present study, following treatment for 24,48 and $72 \mathrm{~h}$, genistein significantly inhibited the proliferation of MCF-7 cells in a concentration-dependent manner. Notably, ER $\alpha$ expression was downregulated while proliferation was inhibited in MCF-7 cells exposed to genistein.

$\mathrm{ER} \alpha$ is a member of the steroid receptor superfamily that regulates processes such as growth and differentiation in various target cells by affecting transcription. ER $\alpha$ also plays an important role in the development and progres- sion of breast cancer. A novel strategy for breast cancer chemotherapy is the identification of $\mathrm{ER} \alpha$ regulators among phytoestrogens $(22,23)$.

Obesity is associated with an increased risk of developing cancer; in particular, obesity plays an important role in the pathogenesis of breast cancer since it causes altered adipokine levels, elevated circulating estrogen levels and insulin resistance (24). The differentiation of 3T3-L1 preadipocytes results in cells with the biochemical characteristics of adipocytes (for example, increased ER $\alpha$ expression). Upon the induction of differentiation in 3T3-L1 cells following inducer treatment for $48 \mathrm{~h}, \mathrm{ER} \alpha$ expression was significantly downregulated by genistein to an extent similar to that in 3T3-L1 preadipocytes. Based on these results, genistein may be associated with the proliferation of MCF-7 cells and differentiation of 3T3-L1 cells via ER $\alpha$ expression.

When genistein was applied to MCF-7 and 3T3-L1 cells, cyclin D1 expression was reduced. Cyclin D1 is a prominent target of estrogens in breast cancer cells and its induction is important for the progression of cells through the G1 phase of the cell cycle (25). The results of several studies suggest that cyclin D1 is overexpressed in breast cancer $(26,27)$ and that it is associated with ER positivity in breast cancer (28-30).

Furthermore, the induction of apoptosis by genistein is supported by evidence demonstrating that the apoptotic cell population was increased in MCF-7 and 3T3-L1 cells. Apoptosis is essential for tissue development and homeostasis. The mechanism of apoptosis involves a balance between factors that induce and those that inhibit the process. Pro-apoptotic agents have been proposed as a novel strategy not only for cancer chemotherapy but also for the treatment of obesity (31). It has been reported $(32,33)$ that the induction of apoptosis in adipocytes, which are otherwise resistant to apoptosis due to high levels of Akt/protein kinase B and Bcl-2, may be a method of reducing adipocyte numbers. In MCF-7 and 3T3-L1 cells, genistein treatment significantly reduced the $\mathrm{Bcl}-2 / \mathrm{Bax}$ ratio by decreasing $\mathrm{Bcl}-2$ expression and increasing 
Bax expression. Bax genes and members of the Bcl-2 family, such as Bcl-2, are involved in the control of apoptotic pathways (34). The decreased expression of Bcl-2 and increased expression of Bax is associated with the response of cancer cell lines to anticancer compounds. In addition, a loss of Bcl-2 expression may promote the induction of apoptosis.

Based on the results of the current study, genistein inhibits the proliferation of MCF-7 and differentiation of 3T3-L1 cells via apoptosis induction and an ER $\alpha$-related pathway. The effects of genistein observed in the present study make it potentially useful for further development as not only a chemotherapeutical agent for breast cancer but also a chemopreventive agent for obesity.

\section{Acknowledgements}

The present study was supported by the Basic Research Program through the National Research Foundation of Korea (NRF) funded by the Ministry of Education, Science and Technology (NRF-2013R1A1A2008595).

\section{References}

1. Liggins J, Bluck LJ, Runswick S, et al: Daidzein and genistein content of fruits and nuts. J Nutr Biochem 11: 326-331, 2000.

2. Liggins J, Bluck LJ, Runswick S, et al: Daidzein and genistein contents of vegetables. Br J Nutr 84: 717-725, 2000.

3. Liggins J, Mulligan A, Runswick S and Bingham SA: Daidzein and genistein content of cereals. Eur J Clin Nutr 56: 961-966, 2002

4. Akiyama T, Ishida J, Nakagawa S, et al: Genistein, a specific inhibitor of tyrosine-specific protein kinases. J Biol Chem 262: 5592-5595, 1987.

5. Ullrich A and Schlessinger J: Signal transduction by receptors with tyrosine kinase activity. Cell 61: 203-212, 1990.

6. Kyle E, Neckers L, Takimoto C, et al: Genistein-induced apoptosis of prostate cancer cells is preceded by a specific decrease in focal adhesion kinase activity. Mol Pharmacol 51: 193-200, 1997.

7. Peeters PH, Keinan-Boker L, van der Schouw YT and Grobbee DE: Phytoestrogens and breast cancer risk. Review of the epidemiological evidence. Breast Cancer Res Treat 77 : 171-183, 2003

8. Qin LQ, Xu JY, Wang PY and Hoshi K: Soyfood intake in the prevention of breast cancer risk in women: a meta-analysis of observational epidemiological studies. J Nutr Sci Vitaminol (Tokyo) 52: 428-436, 2006

9. Iwasaki M and Tsugane S: Risk factors for breast cancer: epidemiological evidence from Japanese studies. Cancer Sci 102: 1607-1614, 2011.

10. Lamartiniere CA, Zhang JX and Cotroneo MS: Genistein studies in rats: potential for breast cancer prevention and reproductive and developmental toxicity. Am J Clin Nutr 68: 1400S-1405S, 1998.

11. de Lemos ML: Effects of soy phytoestrogens genistein and daidzein on breast cancer growth. Ann Pharmacother 35: $1118-1121,2001$.

12. Kittaneh M, Montero AJ and Glück S: Molecular profiling for breast cancer: a comprehensive review. Biomark Cancer 5: 61-70, 2013.

13. Esfahlan RJ,Zarghami N, Esfahlan AJ, et al: The possible impact of obesity on androgen, progesterone and estrogen receptors $(\mathrm{ER} \alpha$ and $\mathrm{ER} \beta)$ gene expression in breast cancer patients. Breast Cancer (Auckl) 5: 227-237, 2011.

14. Williams C and Lin CY: Oestrogen receptors in breast cancer: basic mechanisms and clinical implications. Ecancermedicalscience 7: 370, 2013.
15. Sirtori CR, Arnoldi A and Johnson SK: Phytoestrogens: end of a tale? Ann Med 37: 423-438, 2005.

16. Mueller SO, Simon S, Chae K, et al: Phytoestrogens and their human metabolites show distinct agonistic and antagonistic properties on estrogen receptor alpha (ERalpha) and ERbeta in human cells. Toxicol Sci 80: 14-25, 2004.

17. Bovee TF, Schoonen WG, Hamers AR, et al: Screening of synthetic and plant-derived compounds for (anti)estrogenic and (anti)androgenic activities. Anal Bioanal Chem 390: 1111-1119, 2008.

18. Choi EJ and Kim GH: Antiproliferative activity of daidzein and genistein may be related to ER $\alpha / c$-erbB-2 expression in human breast cancer cells. Mol Med Rep 7: 781-784, 2013.

19. Hsu JT, Hung HC, Chen CJ, et al: Effects of the dietary phytoestrogen biochanin A on cell growth in the mammary carcinoma cell line MCF-7. J Nutr Biochem 10: 510-517, 1999.

20. Choi EJ and Kim T: Equol induced apoptosis via cell cycle arrest in human breast cancer MDA-MB-453 but not MCF-7 cells. Mol Med Rep 1: 239-244, 2008.

21. Rajah TT, Du N, Drews N and Cohn R: Genistein in the presence of 17beta-estradiol inhibits proliferation of ERbeta breast cancer cells. Pharmacology 84: 68-73, 2009.

22. Björnström L and Sjöberg M: Mechanisms of estrogen receptor signaling: convergence of genomic and nongenomic actions on target genes. Mol Endocrinol 19: 833-842, 2005.

23. Liu MM, Huang Y and Wang J: Developing phytoestrogens for breast cancer prevention. Anticancer Agents Med Chem 12: 1306-1313, 2012

24. Iyengar NM, Hudis CA and Dannenberg AJ: Obesity and inflammation: new insights into breast cancer development and progression. Am Soc Clin Oncol Educ Book: 46-51, 2013.

25. Musgrove EA, Lee CS, Buckley MF and Sutherland RL: Cyclin D1 induction in breast cancer cells shortens G1 and is sufficient for cells arrested in G1 to complete the cell cycle. Proc Natl Acad Sci USA 91: 8022-8026, 1994.

26. Buckley MF, Sweeney KJ, Hamilton JA, et al: Expression and amplification of cyclin genes in human breast cancer. Oncogene 8: 2127-2133, 1993

27. Bartkova J, Lukas J, Müller H, et al: Cyclin D1 protein expression and function in human breast cancer. Int J Cancer 57: 353-361, 1994.

28. Barbareschi M, Pelosio P, Caffo O, et al: Cyclin-D1-gene amplification and expression in breast carcinoma: relation with clinicopathologic characteristics and with retinoblastoma gene product, p53 and p21WAF1 immunohistochemical expression. Int J Cancer 74: 171-174, 1997.

29. Utsumi T, Yoshimura N, Maruta M, et al: Correlation of cyclin D1 MRNA levels with clinico-pathological parameters and clinical outcome in human breast carcinomas. Int J Cancer 89: 39-43, 2000.

30. Butt AJ, McNeil CM, Musgrove EA and Sutherland RL: Downstream targets of growth factor and oestrogen signalling and endocrine resistance: the potential roles of c-Myc, cyclin D1 and cyclin E. Endocr Relat Cancer 12 (Suppl 1): S47-S59, 2005.

31. Herold C, Rennekampff HO and Engeli S: Apoptotic pathways in adipose tissue. Apoptosis 18: 911-816, 2013.

32. Nelson-Dooley C, Della-Fera MA, Hamrick M and Baile CA: Novel treatments for obesity and osteoporosis: targeting apoptotic pathways in adipocytes. Curr Med Chem 12: 2215-25, 2005.

33. Zhang Y and Huang C: Targeting adipocyte apoptosis: a novel strategy for obesity therapy. Biochem Biophys Res Commun 417: $1-4,2012$

34. Cory S and Adams JM: Killing cancer cells by flipping the Bcl-2/Bax switch. Cancer Cell 8: 5-6, 2005. 